\title{
Tourism trends: lifestyle developments and the links to solo tourism.
}

\author{
LEITH, C.
}

2020 


\title{
Tourism trends: lifestyle developments and the links to solo tourism
}

\author{
Craig Leith
}

\begin{abstract}
Purpose - The purpose of this paper is to propose drivers that may impact the development of solo tourism in the near future.

Design/methodology/approach - This paper identifies and briefly examines four key factors that, it is suggested, will be significant in solo tourism in the near future.

Findings - It is proposed that future solo tourism will be increasingly fragmented based on the desires, living circumstances and motivations of the individual. A key element will be the level of solitude or controlled or uncontrolled companionship that the individual desires. Three possible personas of the future solo tourist are highlighted.
\end{abstract}

Originality/value - Solo tourism is currently underresearched, and this paper provides a starting point in looking specifically at the varying motivations and behaviours of the solo tourist.

Keywords Stigma, Companionship, Digital anchor, Solitude, Solo-tourism, Lifestyles

Paper type Research paper

\section{Introduction}

There is an increase in solo lifestyle choices, particularly living alone (Klinenberg, 2012), with "Ioner living" being identified as a key global consumer trend for the coming decade and beyond (Euromonitor, 2019). Reasons for living alone will vary greatly between individuals and cultures, as well as globally, but can include lower marriage rates, higher divorce rates and greater employment movement. It may also simply be down to individual preference. The level of choice will vary considerably, with some individuals seeing it as a desirable living state, whereas others may have loner living thrust upon them for particular external, or internal, reasons. With a focus on a single, rather than couple, lifestyle, Budgeon (2008) notes the importance of choice in validating and embracing singleness. Santos et al. (2017) concluded that a move towards an individualist society was a global trend, whereas in her work on city living, Tonkiss (2003) refers to the concept of indifference of a community and the individual solitude of shared urban living.

However, the continued growth of living alone only provides a degree of insight into the wider concept of solitude and how this may impact as a trend within tourism. Simply living alone does not mean that one experiences, or indeed seeks, solitude within their lifestyle. An individual living alone may have a degree of intensive social interaction within other areas of their personal and work lives. Alternatively, someone who lives in a household with other family or friends may experience a high level of solitude in other ways, such as in their choices of leisure pursuits.

Individuals can experience times of solitude in other aspects of their life, including work, leisure activities and commuting. This is even before we explore how use of digital communication and online activity impacts our level of solitude or social interaction. It can be argued that it is impossible to experience solitude if engaged in online activity, even if
Craig Leith is based at School of Creative and Cultural Business, Robert Gordon University, Aberdeen, UK.
Received 1 November 2019 Revised 28 December 2019 Accepted 6 January 2020

(C) Craig Leith. Published in Journal of Tourism Futures. Published by Emerald Publishing Limited. This article is published under the Creative Commons Attribution (CC BY 4.0) license. Anyone may reproduce, distribute, translate and create derivative works of this article (for both commercial and non-commercial purposes), subject to full attribution to the original publication and authors. The full terms of this license may be seen at http://creativecommons. org/licences/by/4.0/legalcode 
physically alone. Velleman (2013) posits that enjoying solitude involves having awareness of enjoying one's own company. Conscious effort to entertain oneself by keeping busy actually is a distraction from solitude. In this argument, an individual in physical isolation cannot be said to being experiencing solitude if they are actively engaged in any activity. The final key consideration within this mix is the level of choice for solitude. A person may seek out a regular period every day for solitude, and another may crave the briefest moment of meaningful social interaction.

MINTEL (2018) recognise the need to segment solo tourists in terms of those individuals who go on holiday alone and those who may travel alone but with the set intention of joining others such as on a tour group. There also exists the potential for an individual to meet other solo tourists online to arrange to meet while on holiday - either for the duration or for agreed periods within the holiday. The backpacker is a well-established tourist type, who often sets out as a solo tourist; but an important factor is the aim to meet many other like-minded travellers (Murphy, 2001). There is also the solo tourist who desires little, if any, interaction with anyone else during their holiday. The experience will depend to a large degree on the level of solitude or controlled (or uncontrolled) companionship which the individual desires. This all indicates that the solo tourist now, and of the future, can increasingly be defined by their own individual tourism needs, motivations and behaviours that can differ greatly from one solo tourist to another. This paper suggests that the "type" of solo tourist may be heavily dependent on the four specific drivers discussed here:

1. the search for solitude;

2. the search for social interaction;

3. lessening of the solitary stigma; and

4. the digital anchor to others.

\section{The search for solitude}

It can be expected that our lifestyles will become increasingly busy in coming years. For many, the overlap between working and leisure hours is becoming more pronounced to such a degree that many employers are concerned over well-being of employees. For wider economic and social reasons, there have been significant changes to living situations with a variety of "home-share" arrangements more evident. This involves shared living with family, friends or others. In terms of desire for solitude, this paper agrees with the view that solitude does not necessarily require a state of physical isolation but can be experienced when one is in the presence of others but unobserved (Long and Averill, 2003; Detrixhe et al., 2014). Depending on the individual, their personal motivations, the context and the level of choice, solitude may be a positive or negative experience, with Averill and Sundararajan (2014) stating the importance of choice by defining unwanted isolation as pseudo-solitude, while authentic solitude is achieved through personal choice.

\section{The search for social interaction}

There is a growing awareness of loneliness, which has been described as an "epidemic" (Smith, 2018), indicating clear medical concerns directly linked to this issue. A distinction must be made between loneliness and solitude, (Goodwin and Lockshin, 1992), with the former being negative and indicating a lack of choice in being alone, whereas the latter indicates a positive or negative state, depending on factors including context and level of personal choice. It is suggested that solo tourism allows the individual to take greater control over their social interaction in terms of who they spend time with, to what extent and even to play with their own identity through their interactions with others. 


\section{Lessening of the solitary stigma}

The concept of the "public gaze" suggests the subjective nature of how we feel others see us. Eating in a public space alone for example invites the gaze, and perceived judgement, of others. We make decisions in our behaviour that to some degree take account of this gaze. It is one thing to eat a sandwich in a café alone - quite another to book a table for one in a romantic restaurant on Valentine's Day. An individual may be reluctant to partake in a solitary activity if it was public, and they ran the perceived risk of being observed and judged (Ratner and Hamilton, 2015). However, DePaulo (2015) argues this concern of being negatively judged partaking in a solo activity publicly is unwarranted. It is suggested that the future solo tourist will have less concern over judgement from the public gaze, which will impact on their decision making and behaviour. This perhaps depends on what extent society as a whole moves towards becoming more or less judgemental about lifestyle choices in the near future.

\section{The digital anchor to others}

A significant driver to recent growth in solo tourism has been the ubiquitous use of online communication (Paris, 2012), which has made the prospect of solo tourism less daunting for many due to the sheer amount of advice, reviews and other forms of digital support available from a range of online communities and services (White and White, 2007).

Enjoying holidays with others, such as friends, family or co-members of a tour group is popular as the norm for many reasons. Others provide company, a sense of security, a sharer of experiences as well as serving a range of other purposes. The solo tourist potentially has nobody to fulfil these roles. However, we know that simply is not true. Our friends (and therefore their company, advice and ability to share in our experiences) are with us virtually in many ways. We are never alone. Even when out for our Valentine's dinner for one, our friends are only a quick message, video call or supporting emoji away. This potential crutch makes it easier to take on new solo experiences, may it be to join an evening class alone, to take a 5-hour solo train journey or to undertake a day long solo walk. All of these pursuits can prove enjoyable with no interaction with friends, but the knowledge that such interaction is available - digitally - may make the experience easier to take on and lead to less anxiety during the class, journey or walk.

\section{The future of solo tourism}

This paper does not intend to make recommendations nor suggest implications for tourism stakeholders. Rather, it aims to move discussion of solo tourism beyond its current limited focus. It is suggested that there will be a continual growth in solo tourism. However, the drivers discussed here indicate that the nature of, and reasons for, solo tourism experiences will greatly depend on the wider social circumstances and personal needs of the individual. To a large degree it will depend on the level of solitude or controlled (or uncontrolled) companionship that one desires from the experience. The key premise of the ideas presented here is that "solo tourism" as a concept will continue to fragment. The individual motivations, behaviour and experience of the solo tourist will depend on a range of internal and external factors. It is suggested that the four drivers identified here will be of particular significance. To conclude, the following descriptions outline three possible future solo tourist personas of 2025 - each of whom are seeking different experiences as a solo tourist, but all dependent to some degree on some of the drivers discussed above:

- Nineteen-year-old Sophie has embarked reluctantly on a gap year travelling around South East Asia and Australia. She knows it should be "character building", but she misses her friends and struggles to meet new people, as she is somewhat shy. Initially, she spent hours every day speaking to friends at home in Scotland via digital platforms. However, recently she has relied less on this, although she finds it a great comfort that 
she is never truly "alone". Although she has started to meet fellow backpackers, often she feels little in common with some people she meets. She enjoys the company, and she is becoming more confident; however she sometimes quietly walks off, unfollows new acquaintances online or simply does not keep to agreed arrangements to meet. She is aware that she is in control of who she spends time with and how, which would not be possible if she was travelling with a group of her established friends.

- Forty-eight-year-old Graeme is married, with two teenage children and a demanding job. This year he has decided to take a 3-day solo holiday to Porto. Beyond checking in with his family each evening for a quick online video chat, he barely speaks to anyone other than to order a glass of wine or food. He walks, he sits and watches, and he daydreams. He does not even open his newly purchased book until at the airport for his flight home. There was a brief moment of self-conciseness when he walked into a recommended restaurant for dinner to be faced with many couples and larger laughing groups enjoying their Saturday night. However, dotted throughout the restaurant were several other contented solo diners. Once seated, it was clear nobody was giving Graeme a first thought or a second glance. He returns home recharged to hugs and realises he has experienced real solitude for the first time in many years. Excited now for the joys and challenges of both work and family life, he is thinking Gdansk or Riga next year.

- Thirty-three-year old Steven is enjoying his 10-day escorted group tour in Djibouti, his 14th such trip. Such holidays have allowed him to experience countries throughout the world - including Antarctica. However, the main reason he joins the tours is for the opportunity to meet new people. He is proud to have friends from all over the world, who he has met throughout his travels. At home, Steven has an enjoyable job and a small close network of friends. He is happily single and lives alone, and although he would be happy to meet a partner, this is difficult due to the small town he now lives in. He does hope that love lies ahead in one of his group holidays, but until then, he enjoys and looks forward to the friendships and close social interaction he experiences every single time.

\section{References}

Averill, J.R. and Sundararajan, L. (2014), "Experiences of solitude: Issues of assessment, theory and culture", in Coplan, R.R. and Bowker, J.C. (Eds), The Handbook of Solitude: Psychological Perspectives on Social Isolation, Social Withdrawal, and Being Alone, John Wiley \& Sons, pp. 90-108.

Budgeon, S. (2008), "Couple culture and the production of singleness", Sexualities, Vol. 11 No. 3, pp. 301-325.

DePaulo, B. (2015), "Alone: The badass psychology of people who like being alone", p. 103.

Detrixhe, J.J., Samstag, L.W., Penn, L.S. and Wong, P.S. (2014), "A lonely idea: solitude's separation from psychological research and theory”, Contemporary Psychoanalysis, Vol. 50 No. 3, pp. 310-311.

Euromonitor (2019), International Top 10 Global Consumer Trends, Euromonitor International, London.

Goodwin, C. and Lockshin, L. (1992), "The solo consumer: unique opportunity for the service marketer", Journal of Services Marketing, Vol. 6 No. 3, pp. 27-36.

Klinenberg, E. (2012), Going Solo: The Extraordinary Rise and Surprising Appeal of Living Alone, Duckworth Overlook, London.

Long, C.R. and Averill, J.R. (2003), "Solitude: an exploration of benefits of being alone", Journal for the Theory of Social Behaviour, Vol. 33 No. 1, pp. 21-44.

MINTEL (2018), Solo Holidays UK.

Murphy, L. (2001), "Exploring social interactions of backpackers", Annals of Tourism Research, Vol. 28 No. 1, pp. 50-67. 
Paris, C.M. (2012), "Flashpackers: an emerging Sub-Culture?", Annals of Tourism Research, Vol. 39 No. 2, pp. 1094-1115.

Ratner, R.K. and Hamilton, R.W. (2015), "Inhibited from bowling alone", Journal of Consumer Research, Vol. 42, pp. 266-283.

Santos, H.C., Varnum, M.E.W. and Grossman, I. (2017), "Global increases in individualism", Psychological Science, Vol. 28 No. 9, pp. 1228-1239.

Smith, J. (2018), "Loneliness on it's way to becoming britain's most lethal condition", The Conversation, available at: www.theconversation.com/loneliness-on-its-way-to-becoming-britains-most-lethal-condit ion-94775 (accessed 28 October 2019).

Tonkiss, F. (2003), "The ethics of indifference: community and solitude in the city", International Journal of Cultural Studies, Vol. 6 No. 3, pp. 297-311.

Velleman, J.D. (2013), "Sociality and solitude", Philosophical Explorations, Vol. 16 No. 3, pp. 324-335.

White, N.R. and White, P.B. (2007), "Home and away: tourists in a connected world", Annals of Tourism Research, Vol. 34 No. 1, pp. 88-104.

\section{Corresponding author}

Craig Leith can be contacted at: c.leith1@rgu.ac.uk

For instructions on how to order reprints of this article, please visit our website: www.emeraldgrouppublishing.com/licensing/reprints.htm

Or contact us for further details: permissions@emeraldinsight.com 